Int. J. Electrochem. Sci., 14 (2019) 9415 - 9427

\title{
Corrosion Inhibition Effect of Stem Extract of Brahmi (Bacopa monnieri) for Mild Steel in Hydrochloric Acid
}

\author{
Chao Wang ${ }^{1,2}$, Peng Liu ${ }^{1,2}$, Pengcheng Liu ${ }^{1,2, *}$, Lei Li ${ }^{1,2}$, Jie Liu ${ }^{1,2}$ \\ ${ }^{1}$ School of Energy Resources, ${ }^{1}$ China University of Geosciences, Beijing, 100083, China. \\ ${ }^{2}$ Key laboratory of strategy evaluation for Shale gas, Ministry of Land and Resources, Beijing 100083, \\ China. \\ *E-mail: liupengcheng8883@sohu.com; liupengcheng8883@126.com
}

doi: $10.20964 / 2019.10 .33$

Received: 3 June 2019 / Accepted: 30 July 2019 / Published: 30 August 2019

\begin{abstract}
The stem extract of Bacopa monnieri (BMSE) was examined as potential corrosion inhibitor of mild steel in $1 \mathrm{M}$ hydrochloric acid $(\mathrm{HCl})$ media using weight loss, electrochemical and surface studies. The weight loss results discovered that samples covered with BMSE showed less weight loss compared to the samples without BMSE. The electrochemical tests including electrochemical impedance spectroscopy (EIS), and potentiodynamic polarization (PDP) showed good mitigation efficiency of BMSE in $1 \mathrm{M} \mathrm{HCl}$ solution. The mixed shift of the anodic and cathodic slopes advised that the inhibitor represented as mixed category. The surface studies were completed using scanning electron microscopyenergy dispersive spectra (SEM-EDS) and atomic force microscopy (AFM). Both the studies displayed even surface in existence of BMSE and rough surface in its absence. All the experimental results are in decent pact respectively.
\end{abstract}

Keywords: Mild steel, Corrosion inhibition, Bacopa monnieri, EIS, AFM, SEM-EDS

\section{$\underline{\text { FULL TEXT }}$}

(C) 2019 The Authors. Published by ESG (www.electrochemsci.org). This article is an open access article distributed under the terms and conditions of the Creative Commons Attribution license (http://creativecommons.org/licenses/by/4.0/). 